\title{
SENSIBILIDADE DE LINHAGENS CELULARES FRENTE À MELITINA ISOLADA DE VENENO DE ABELHA
}

Recebido: 05/02/2016

\author{
PICOLI, Tony ${ }^{1}$; \\ PICH, Cloé Schiavon ${ }^{2}$; \\ LOPES, Matheus Gomes ${ }^{3}$; \\ TEIXEIRA, Alessandra Goulart ${ }^{4}$; \\ FISCHER, Geferson ${ }^{5}$.
} Aceito: 07/07/2016

\footnotetext{
${ }^{1}$ Doutorando do Programa de Pós-Graduação em Veterinária, UFPEL; ${ }^{2}$ Técnica laboratorial, Laboratório de Virologia e Imunologia, UFPEL; ${ }^{3}$ Mestrando do Programa de Pós-Graduação em Veterinária, UFPEL; ${ }^{4}$ Graduanda em Medicina Veterinária, UFPEL; ${ }^{5}$ Professor Adjunto do Departamento de Veterinária Preventiva, UFPEL.
}

\section{RESUMO}

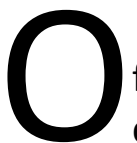

estudo da composição e dos efeitos do veneno de abelha têm revelado efeitos farmacológicos, terapêuticos e antimicrobianos e estimulou a análise de seus constituintes de maneira isolada. Melitina, o principal componente da apitoxina, foi avaliada quanto à sua toxicidade frente a diferentes linhagens celulares. Para tanto, células MDBK, MDCK, CRFK, RK13 e Vero foram cultivadas e submetidas à exposição com melitina em concentrações que variaram de 1 a $10 \mu \mathrm{g} / \mathrm{mL}$ para obtenção das concentrações citotóxicas para $50 \%$ e $90 \%$ dos cultivos celulares $\left(\mathrm{CC}_{50}\right.$ e $\mathrm{CC}_{90}$, respectivamente) através da avaliação de viabilidade celular pelo ensaio de redução do MTT. Cultivos foram preparados e tratados com as $\mathrm{CC}_{50}$ e $\mathrm{CC}_{90}$ e permaneceram expostos por diferentes períodos quando novamente tiveram sua viabilidade celular avaliada pelo mesmo método. As $\mathrm{CC}_{50}$ e $\mathrm{CC}_{90}$ $(\mu \mathrm{g} / \mathrm{mL})$ foram, respectivamente: $\operatorname{MDBK}(2,3$ e 2,7), $\operatorname{MDCK}(2,8$ e 3,2), CRFK $(3,3$ e 3,7), RK13 $(4,1$ e 4,7$)$ e Vero $(3,7$ e 4,2). As células CRFK e Vero mostraram-se mais resistentes aos 5 minutos de exposição, visto que, na $\mathrm{CC}_{50}$ de melitina, apresentaram a mesma viabilidade celular em relação ao controle de células. Nos demais períodos avaliados, a viabilidade celular de todas as linhagens apresentou-se inferior ao controle de células $(p<0,05)$, diminuindo a viabilidade em função do aumento do tempo de exposição e da concentração. Concluiu-se que a melitina apresentou toxicidade frente às linhagens celulares estudadas, dependente do tempo e da concentração.

Palavras-chave: Viabilidade celular. Apitoxina. MTT. 


\section{INTRODUÇÃO}

A maioria das substâncias orgânicas conhecidas é proveniente da natureza, seja do reino vegetal, animal ou mineral. Atualmente, com as técnicas disponíveis, seria impossível a mensuração da variedade e da complexidade das micromoléculas que constituem os metabólitos secundários de organismos do reino animal ou vegetal. Esta enorme diversidade é consequência direta de milhões de anos de evolução dos organismos, o que levou a um elevado número de formas de proteção e resistência às intempéries do clima, poluição e predadores (MONTANARI; BOLZANI, 2001).

Algumas espécies de abelhas são capazes de produzir e injetar apitoxina na defesa de sua colmeia. Esta apitoxina é o próprio veneno, que é composto por um complexo único de componentes e secretado por uma glândula especializada existente nas abelhas operárias, sendo armazenado em uma vesícula até o momento de sua aplicação, mediante ferroada (BENTON et al., 1963). É uma mistura complexa de compostos nitrogenados, que correspondem a mais de $90 \%$ de seu peso seco, contendo diversos componentes biologicamente ativos, incluindo enzimas, peptídeos e aminas biogênicas, que conferem uma ampla variedade de propriedades farmacológicas, como ações anti-inflamatórias, antivirais e antitumorais (DE ABREU et al., 2010; GLÄTTLI et al., 2006; MÜLLER et al., 1997; TERWILLIGER; EISENBERG, 1982).

Os estudos sobre a composição e o modo de ação do veneno de abelhas melíferas se intensificaram a partir da década de 1950. Três classes de componentes protéicos são responsáveis pela toxicidade do veneno: enzimas (fosfolipase A2 e hialuronidase), grandes peptídeos (melitina, apamina e peptídeo degranulador de mastócitos) e pequenas moléculas (peptídeos e aminas biogênicas), que possuem atividades alérgicas e farmacológicas (CARDOSO et al., 2003).

A melitina é um conhecido peptídeo tóxico, solúvel em água, presente no veneno de abelhas melíferas, compreendendo aproximadamente $50 \%$ de seu peso seco (CRUZ-LANDIM; ABDALLA, 2002; HABBERMAN, 1972). Com apenas 26 aminoácidos em sua conformação, é a toxina mais ativa do veneno e, quando armazenada na vesícula específica, arranja-se de forma tetramérica diminuindo sua toxicidade (CARDOSO et al., 2003). Entretanto, quando o 
veneno é liberado, dissocia-se e, individualmente, sua forma monomérica passa a ter uma alta toxicidade. Ainda, quando associada à fosfolipase A2, também presente na apitoxina, tem sua ação amplificada e modula a ação das fosfolipases, aumentando suas ações catalíticas (CARDOSO et al., 2003; KOUMANOV et al., 2003).

A melitina, embora possua atividades antibacteriana, antifúngica, antiviral, anti-inflamatória e antitumoral (BROWN et al., 1980; GLÄTTLI et al., 2006; HABERMANN, 1972; TERWILLIGER; EISENBERG, 1982), possui também rápida ação citolítica, desestabilizando membranas celulares e liberando conteúdo citoplasmático de diversos tipos celulares (DEMPSEY, 1990). A atividade hemolítica da melitina é seu efeito biológico mais característico, usado para identificação do peptídeo em frações de veneno (TOSTESON el al., 1985), e a capacidade lítica não se restringe às células animais, uma vez que apresenta capacidade antibacteriana e antifúngica (ASHTHANA et al., 2004).

O Código de Nuremberg estabelece que antes de administrar qualquer novo fármaco ao ser humano, deve-se conhecer: composição química, método de preparação e grau de pureza; testes de toxicidade in vitro e in vivo em diferentes espécies animais; análise patológica em diversos órgãos animais; absorção, excreção e concentração nos tecidos, bem como se ocorre interação com outros medicamentos e alimentos (CALIXTO; SIQUEIRA JÚNIOR, 2008; LIMA et al., 2003). Já os comitês de ética e experimentação animal também aconselham testes in vitro antes da utilização em animais, visando o bem-estar e diminuindo o número de animais em experimentação. Dessa forma, este estudo objetivou avaliar a citotoxicidade da melitina purificada de veneno de abelha em cinco diferentes linhagens celulares provenientes de animais: Madin-Darby Bovine Kidney (MDBK, células renais de bovino), Madin-Darby Canine Kidney (MDCK, células renais de canino), Crandell Rees Feline kidney (CRFK, células renais de felino), Rabit Kidney (RK13, células renais de coelho) e African Green Monkey Kidney (Vero, células renais de macaco verde africano).

\section{MATERIAL E MÉTODOS}

\section{Material}

A melitina foi adquirida comercialmente (Sigma-Aldrich Corp., St. Louis, MO) com pureza de 85\% e dissolvida utilizando tampão salina-fosfato estéril pH 7,2 (PBS) como diluente, sendo 
estocada na concentração de $1 \mathrm{mg} / \mathrm{mL}$ em alíquotas de $50 \mu \mathrm{L}$ sob temperatura inferior a -70 ${ }^{\circ} \mathrm{C}$. As diferentes concentrações dos compostos utilizados nos experimentos foram realizadas

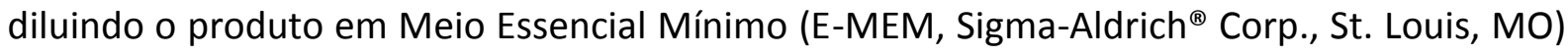
suplementado com antibióticos: penicilina (Sigma-Aldrich ${ }^{\circledR}$, USA), estreptomicina $\left(\right.$ Vetec $^{\circledR}$,

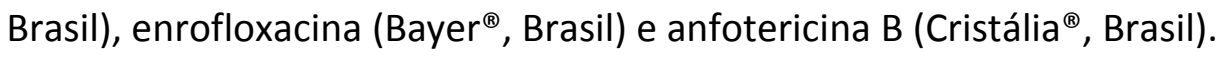

Células MDBK, MDCK, CRFK, RK13 e Vero foram adquiridas do banco de células do Laboratório de Virologia e Imunologia da Faculdade de Veterinária da Universidade Federal de Pelotas e permaneceram em ampolas estocadas em nitrogênio líquido até o momento do uso. Meio E-MEM suplementado com $10 \%$ de soro fetal bovino (SFB, Gibco ${ }^{\circledR}$, Grand Island, NY) foi utilizado para o cultivo celular em microplacas de poliestireno com 96 cavidades de fundo chato (KASVI ${ }^{\circledR}$, Brasil). Dimetilsulfóxido (DMSO) e reagente MTT (3-(4,5 dimetiltiazol2yl)-2-5-difenil-2H tetrazolato de bromo) para testes de viabilidade celular também foram adquiridos comercialmente (Sigma-Aldrich ${ }^{\circledR}$ Corp., St. Louis, MO).

\section{Cultura de células}

As linhagens celulares foram descongeladas e cultivadas em garrafas de cultivo celular contendo E-MEM suplementado com SFB, hermeticamente fechadas e mantidas em estufa sob temperatura de $37^{\circ} \mathrm{C}$. Para o cultivo celular em microplacas, células em fase exponencial de crescimento foram diluídas em E-MEM suplementado com $10 \%$ de SFB até alcançar a concentração de $3 \times 10^{4}$ células/mL e transferidas para microplacas com 96 cavidades (100 $\mu \mathrm{L} /$ cavidade). Após 24 horas em estufa úmida $37{ }^{\circ} \mathrm{C}$ com $5 \%$ de $\mathrm{CO}_{2}$ e confluência do tapete celular aproximada de $80 \%$, os cultivos estavam prontos para os experimentos. As células utilizadas em todas as etapas encontravam-se em fase exponencial de crescimento.

\section{Ensaios de citotoxicidade}

Após crescimento celular, o meio foi cuidadosamente aspirado e melitina foi acrescida aos poços (100 $\mu \mathrm{L} /$ poço) nas diferentes concentrações (1 a $10 \mu \mathrm{g} / \mathrm{mL}$ ). As placas permaneceram novamente em estufa úmida por 24 horas. Como controles foram utilizadas células das cinco linhagens, mantidas em E-MEM suplementado, sem nenhum tipo de tratamento. O ensaio de redução do MTT foi utilizado para determinação da viabilidade celular após os tratamentos, segundo Mosmann (1983), com pequenas modificações. 
Após a incubação com os tratamentos, o sobrenadante foi cuidadosamente aspirado e foram transferidos $50 \mu \mathrm{L} /$ poço de solução $\mathrm{MTT}$ a $1 \mathrm{mg} / \mathrm{mL}$ e as placas novamente foram incubadas sob as mesmas condições por 4 horas. Após, o sobrenadante foi removido e transferidos 100 $\mu \mathrm{L} /$ poço de dimetilsulfóxido para solubilização dos sais de formazan gerados. Depois de 15 minutos de agitação constante as placas foram submetidas à espectrofotometria e as absorbâncias foram calculadas sob comprimento de onda de $492 \mathrm{~nm}$. As porcentagens de viabilidade celular foram calculadas através da fórmula AT/AC x 100, onde AT e AC indicam, respectivamente, a absorbância obtida dos poços com células tratadas e absorbância obtida nos poços com células controle. A Concentração citotóxica para 50\% e $90 \%$ dos cultivos celulares $\left(\mathrm{CC}_{50}\right.$ e $\mathrm{CC}_{90}$, respectivamente) foi calculada pela fórmula de Reed e Muench (1938). Os testes foram realizados com dez repetições.

Após a obtenção das $\mathrm{CC}_{50}$ e $\mathrm{CC}_{90}$ de melitina perante as linhagens celulares estudadas, novas microplacas foram utilizadas para cultivo celular nas mesmas condições anteriormente descritas e, após confluência do tapete celular e retirada do meio dos poços, $100 \mu \mathrm{L}$ das $\mathrm{CC}_{50}$ e $\mathrm{CC}_{90}$ de melitina para cada célula foram transferidos em sextuplicata sobre os tapetes celulares. Esses tratamentos mantiveram-se em contato com as células por 5, 10, 15 minutos, uma e duas horas. Após esses períodos, as placas foram submetidas ao ensaio de redução do MTT para avaliar a viabilidade celular.

Os resultados foram submetidos à análise estatística por meio de análise de variância com comparação entre médias através do teste LSD e adotou-se um nível de significância de 95\%.

\section{RESULTADOS E DISCUSSÃO}

As $\mathrm{CC}_{50}$ e $\mathrm{CC}_{90}$ de melitina, para as linhagens celulares estudadas, encontram-se dispostas na Tabela 1. Ao microscópio óptico invertido, as células apresentaram-se com tamanho reduzido e aspecto arredondado, com posterior perda de aderência. A intensidade desses sinais foi proporcional à concentração de melitina utilizada. Nas concentrações mais elevadas de melitina (acima de $7 \mu \mathrm{g} / \mathrm{mL}$ ), gradativamente houve destruição de células, sendo impossível identificá-las.

As taxas de morte celular encontradas em todas as linhagens celulares tratadas com melitina apresentaram-se com características dose-dependente, concordando com diversos autores 
(CERNE et al., 2013; MAHER; MCCLEAN, 2006, 2008; OWNBY et al., 1997; PRATT et al., 2005; SU et al., 2001). Conforme esperado, as menores taxas de morte celular foram encontradas nas menores concentrações testadas, aumentando gradativamente conforme aumentava a concentração de melitina.

Tabela 1 - Concentrações citotóxicas 50\% e 90\% de melitina em diferentes linhagens celulares.

\begin{tabular}{ccc}
\hline \multirow{2}{*}{ Linhagem celular } & \multicolumn{2}{c}{ Melitina $(\mu \mathrm{g} / \mathrm{mL})$} \\
\cline { 2 - 3 } & $\mathrm{CC}_{50}$ & $\mathrm{CC}_{90}$ \\
\hline MDBK & 2,3 & 2,7 \\
MDCK & 2,8 & 3,2 \\
CRFK & 3,3 & 3,7 \\
RK13 & 4,1 & 4,7 \\
Vero & 3,7 & 4,2 \\
\hline
\end{tabular}

Zhou et al. (2013), ao tratarem células HepG2 com melitina, encontraram $\mathrm{CC}_{50}$ de 2,11 $\mu \mathrm{g} / \mathrm{mL}$ sob incubação de 24 horas e $1,85 \mu \mathrm{g} / \mathrm{mL}$ sob incubação de 48 horas, demonstrando também uma característica tempo-dependente. Esses autores ainda comprovaram a atividade tóxica de melitina dose-tempo-dependente, realizando tratamento das células com $0,5,1,2,5$ e $10 \mu \mathrm{g} / \mathrm{mL}$ de melitina e obtiveram taxas de inibição do crescimento celular de, respectivamente, $15,18 \%, 21,73 \%, 47,72 \%, 85,54 \%$ e $93,54 \%$ quando tratadas por 24 horas e $19,20 \%, 26,49 \%, 55,27 \%, 92,08 \%$ e $95,91 \%$ quando tratadas por 48 horas. Entretanto, Hu et al. (2006) já haviam descrito efeito citotóxico dose-tempo-dependente do veneno de abelha íntegro ao usá-lo como tratamento em células e realizar avaliação através da redução do MTT.

Jo et al. (2012) relataram que a administração de veneno de abelha $(1-5 \mu \mathrm{g} / \mathrm{mL})$ e de melitina $(0,5-2 \mu \mathrm{g} / \mathrm{mL})$ inibiram de modo dose-dependente a proliferação de células cancerosas ovarianas (linhagens SKOV3 e PA-1). Estes autores afirmaram que veneno de abelha inibiu o crescimento de células SKOV3 com $\mathrm{CC}_{50}$ de $1,5 \mu \mathrm{g} / \mathrm{mL}$ e melitina inibiu com $\mathrm{CC}_{50}$ de $3,8 \mu \mathrm{g} / \mathrm{mL}$. O crescimento de células PA-1 foi inibido com $\mathrm{CC}_{50}$ de $1,2 \mu \mathrm{g} / \mathrm{mL}$ de apitoxina íntegra e com $\mathrm{CC}_{50}$ de $2,6 \mu \mathrm{g} / \mathrm{mL}$ de melitina isolada de apitoxina. 
A ação da melitina sobre as células concentra-se sobre as membranas lipídicas, causando permeabilização, formação de poros artificiais, rompimento e lise (LADOKHIN; WHITE, 2001; LEE et al., 2008; RAGHURAMAN; CHATTOPADHYAY, 2007; ZHANG et al., 2011). A interação de melitina com as membranas fosfolipídicas foi primeiramente descrita por Terwilliger et al. (1982) e comprovada por diversos autores com os mais variados experimentos (GÓMARA et al., 2003; LEE et al., 2013; WU et al., 2011; YANG et al., 2001). Os mecanismos de atuação propostos sobre as membranas foram denominados "modelo barril" e "modelo carpete". O primeiro, através de agregados de melitina alinhados perpendicularmente à superfície da membrana, produz rupturas em formato toroidal (em forma de barril). O "modelo carpete", cursa com uma grande quantidade do peptídeo que se distribui paralelamente na superfície da membrana e interage eletrostaticamente com as cabeças dos lipídeos, desorganizando a bicamada lipídica de modo semelhante a um detergente e, dessa forma, causa permeabilização (BECHINGER, 1999; BENACHIR; LAFLEUR, 1995; GORDON-GROSSMAN et al., 2009; GORDON-GROSSMAN et al., 2012; OREN; SHAI, 1998).

Lu et al. (2013) estudaram o comportamento dinâmico de bicamadas lipídicas quando interagem com melitina e os resultados demonstraram que após as interações com a membrana, há a liberação de lipídeos e o rompimento da curvatura natural da bicamada. Isso leva a uma micelização dos lipídeos liberados e, assim, a célula passa a apresentar aberturas em sua membrana, o que desestabiliza o equilíbrio de íons e líquidos e pode permitir a passagem de moléculas de baixo peso molecular, levando a célula à morte.

Zhou et al. (2013), através de citometria de fluxo, indicaram que células HepG2 tratadas com 0,1 , 2 e $5 \mu \mathrm{g} / \mathrm{mL}$ de melitina durante 24 horas apresentaram taxas de apoptose de $0 \%, 6,5 \%$, $23,7 \%$ e $46,6 \%$, respectivamente. O fluoróforo Annexin $V$ conjugado com isotiocianato de fluoresceína tem afinidade pela fosfatidilserina, um componente fosfolipídico normalmente encontrado no lado citosólico de membranas celulares (JORISSEN et al, 2001) e, quando uma célula passa pelo processo de apoptose, a fosfatidilserina não está mais restrita apenas ao lado interno da membrana e é reconhecida pelo fluoróforo (VERMES et al., 1995). Dessa forma, comprovou-se o poder da melitina em causar a apoptose celular, porém os mesmos autores encontraram taxas de necrose, quando a membrana nuclear também é rompida e 
iodeto de propídeo se liga ao material genético. Portanto sugere-se que em etapas iniciais da ação da melitina sobre as células, apoptose seja detectada e, em etapas posteriores em função do tempo de exposição, seja detectada necrose celular. Entretanto, análise de viabilidade celular pelo método da redução do MTT avalia apenas a funcionalidade mitocondrial (MOSMANN, 1983) e processos de apoptose podem estar em andamento e não são observados.
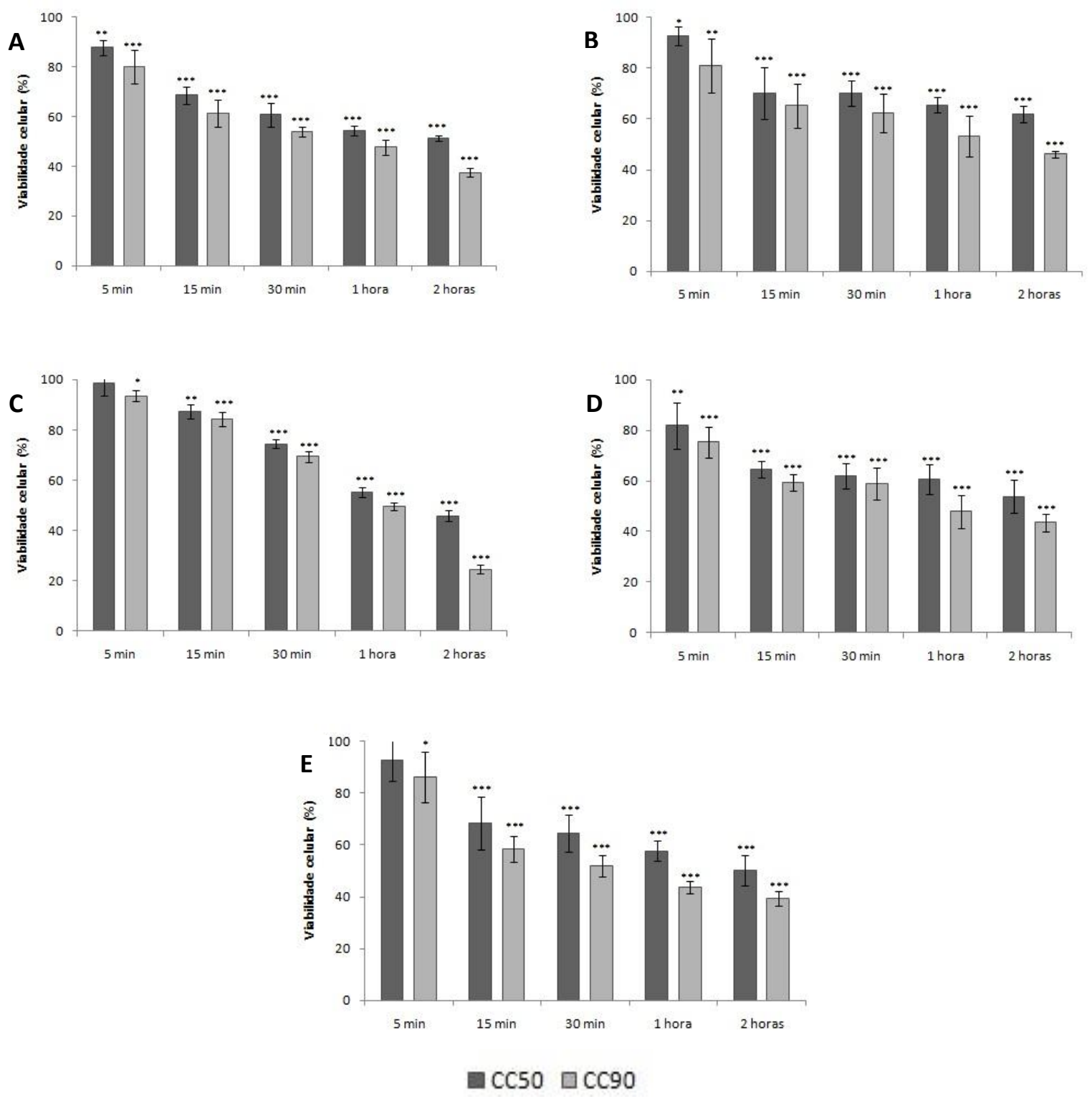

Diferença estatística entre os tempos de exposição à CC50 e CC90 de melitina com o controle de células sem tratamento através do teste $L S D .{ }^{*} p<0,05,{ }^{* *} p<0,01, * * * p<0,001$

Figura 1 - Viabilidade de linhagens celulares submetidas ao tratamento com as concentrações citotóxicas $50 \%$ e 90\% (CC50 e CC90) de melitina em função do tempo de exposição. A: células MDBK, B: células MDCK, C: células CRFK, D: células RK13, E: células Vero. 
A Figura 1 ilustra as taxas de viabilidade celular das linhagens estudadas frente ao tratamento com suas respectivas $\mathrm{CC}_{50}$ e $\mathrm{CC}_{90}$ de melitina em função do tempo de exposição. Ficam claros os efeitos tóxicos dose e tempo dependentes de melitina já expostos por outros autores em diferentes linhagens celulares (JO et al., 2012; MAHER; MCCLEAN, 2006, 2008; ZHOU et al., 2013). Células MDBK expostas por 5 minutos com $\mathrm{CC}_{50}$ de melitina apresentaram $87,65 \% \pm 3,03 \%(p<0,01)$ de viabilidade celular quando comparadas ao controle, e às 2 horas de exposição com $\mathrm{CC}_{90}$ apresentaram apenas 37,51\% $\pm 3,08 \%$ $(p<0,001)$ de viabilidade. Células MDCK submetidas a 15 minutos de exposição com $\mathrm{CC}_{50}$ de melitina apresentaram $70,24 \% \pm 10,09 \%(p<0,001)$ de viabilidade. Células CRFK aos primeiros 5 minutos de exposição sob $\mathrm{CC}_{50}$ de melitina apresentaram 98,57\% \pm 4,84\% $(p>0,05)$ de viabilidade em relação ao controle, porém às 2 horas de exposição frente à $\mathrm{CC}_{90}$ de melitina apresentaram apenas $24,64 \% \pm 1,62 \%(p<0,001)$ de viabilidade celular. Células RK13 com apenas 5 minutos de exposição à melitina sob sua CC $_{50}$ apresentaram $81,77 \% \pm$ $9,1 \%(p<0,01)$ de viabilidade e aos 15 minutos já apresentavam viabilidade de 64,59\% \pm $3,3 \%(p<0,001)$. Já células Vero atingiram $50,18 \% \pm 6,04 \%(p<0,001)$ de viabilidade com 2 horas de exposição à $\mathrm{CC}_{50}$ de melitina.

As doses utilizadas em nosso experimento não permitiram a morte total dos cultivos celulares $\left(\mathrm{CC}_{50}\right.$ e $\left.\mathrm{CC}_{90}\right)$, porém a rápida ação citolítica foi notada. Esta rápida ação citotóxica de melitina foi corroborada por diversos autores que realizaram estudos em diversos cultivos celulares (CERNE et al., 2013; LO et al., 1997; PRATT et al., 2005; SU et al., 2001; WESTON; RAISON, 1998). Estudos através de microscopia fluorescente demonstraram que linfócitos ovinos e humanos apresentaram permeabilidade da membrana celular em segundos de exposição à melitina em doses que variaram de 4,37 a $35 \mu \mathrm{M}$ (SU et al., 2001).

Cerne et al. (2013), ao tratarem células endoteliais humanas com $10 \mu \mathrm{g} / \mathrm{mL}$ de melitina, constataram que em apenas 5 minutos de exposição, a viabilidade do cultivo celular foi reduzida a $40,3 \% \pm 3,5 \%(p<0,001)$, aos 15 minutos a viabilidade foi de pouco mais de $20 \%$ e com 60 minutos de exposição à melitina, não foram observadas células viáveis através da técnica de coloração com azul de tripan. A concentração utilizada por esses autores deveuse a experimentos prévios, em que concentrações de melitina superiores a $7 \mu \mathrm{g} / \mathrm{mL}$ 
causaram contrações na artéria coronária de suínos (CERNE et al., 2010). Experimentos já demonstravam o efeito de melitina sobre células endoteliais de aorta de ratos. Com apenas 5 minutos de exposição à melitina $(10 \mu \mathrm{g} / \mathrm{mL})$, essas células sofreram alterações não reversíveis (RAPOPORT et al., 1989). Através de microscopia fluorescente, foi verificado que após 5 minutos de exposição iniciaram-se os primeiros sinais de alterações morfológicas nas células, os quais gradativamente amplificaram-se até a morte de todo cultivo celular tratado com $10 \mu \mathrm{g} / \mathrm{mL}$ de melitina. Os sinais observados foram encolhimento celular, células com aspecto arredondado, aparecimento de morfologia granular e de vesículas extracelulares ligadas à superfície das membranas externas (CERNE et al, 2013).

Embora a melitina apresente toxicidade celular, o conhecimento dessa característica é fundamental na pesquisa de suas atividades farmacológicas e terapêuticas, visando novos usos para esse peptídeo natural.

\section{CONCLUSÃO}

A melitina, frente às linhagens celulares estudadas, apresentou toxicidade dependente do tempo e da concentração. As células CRFK e Vero, nas concentrações citotóxicas $50 \%\left(\mathrm{CC}_{50}\right)$, com 5 minutos de exposição, não mostraram diferença em relação ao controle. Nos demais períodos e concentrações, todas as linhagens celulares avaliadas apresentaram viabilidade celular inferior ao controle de células e a diferença aumentou conforme o tempo de exposição. 


\section{SENSIBILITY OF CELL LINES TO MELITTIN, ISOLATED FROM BEE VENOM}

\section{ABSTRACT}

$\mathrm{T}$ he study of the composition and effects of honey bee venom has showed pharmacologic, therapeutic and antimicrobial activities and influenced the analysis of its constituents in an isolated way. Melittin, the major constituent of apitoxin, was evaluated for its toxicity against different cell lines. MDBK, MDCK, CRFK, RK13 and Vero cells were cultivated and submitted to treatment with melittin in concentrations ranging from 1 to $10 \mu \mathrm{g} / \mathrm{mL}$ to obtain the cytotoxic concentrations for $50 \%$ and $90 \%$ of cell cultures $\left(\mathrm{CC}_{50}\right.$ and $\mathrm{CC}_{90}$, respectively) through the evaluation of cell viability by $\mathrm{MTT}$ reduction assay. Cultures were prepared and treated with the $\mathrm{CC}_{50}$ and $\mathrm{CC}_{90}$ for different times and had their viability evaluated again by the same method. $\mathrm{CC}_{50}$ and $\mathrm{CC}_{90}(\mu \mathrm{g} / \mathrm{mL})$ were, respectively: $\operatorname{MDBK}$ (2.3 and 2.7), MDCK (2.8 and 3.2), CRFK (3.3 and 3.7), RK13 (4.1 and 4.7) and Vero (3.7 and 4.2). CRFK cells were more resistant to the 5 minutes of exposure as the $\mathrm{CC}_{50}$ of melittin, presented the same cell viability of the cell control. In the other periods evaluated, the cell viability of all cell lines showed to be less than the cell control $(p<0.05)$, reducing their viability due to the increase of the exposure time and concentration. We conclude that melittin showed toxicity in the cell lines studied, depending of time and concentration.

Keywords: Cell viability. Apitoxin. MTT.

\section{SENSIBILIDAD DE LÍNEAS CELULARES FRENTE A MELITINA AISLADA DE VENENO DE ABEJA}

\section{RESUMEN}

$\mathrm{E}$ estudio de la composición y efectos del veneno de abeja de la miel ha mostrado efectos farmacológicos, terapéuticos y antimicrobianos, lo que estimuló al análisis de sus constituyentes en forma aislada. Melitina, el principal constituyente de la apitoxina, se evaluó para su toxicidad frente a las líneas de células diferentes. Para eso, las células MDBK, MDCK, CRFK, RK13 y Vero fueron cultivadas y sometidas al tratamiento con melitina en concentraciones entre 1 a $10 \mathrm{mg} / \mathrm{mL}$ para obtener las concentraciones citotóxicas para $50 \%$ y $90 \%$ de los cultivos celulares $\left(\mathrm{CC}_{50}\right.$ y $\mathrm{CC}_{90}$, respectivamente) a través de la evaluación de la viabilidad celular por el ensayo de reducción de MTT. Se prepararon nuevos cultivos y fueron tratados con el $\mathrm{CC}_{50}$ y $\mathrm{CC}_{90}$, y se expusieron por diferentes periodos de tiempo y se evaluó de nuevo su viabilidad por el mismo método. La $\mathrm{CC}_{50}$ y $\mathrm{CC}_{90}(\mu \mathrm{g} / \mathrm{mL})$ fueron, respectivamente: $\operatorname{MDBK}(2,3$ e 2,7), $\operatorname{MDCK}(2,8$ e 3,2), $\operatorname{CRFK}(3,3$ e 3,7), RK13 (4,1 e $4,7)$ y Vero $(3,7$ e 4,2). Las células CRFK y Vero mostraron ser más resistentes a los 5 minutos de exposición, siendo que en la $\mathrm{CC}_{50}$ de la melitina, presentaron la misma variabilidad celular en relación al control de las células. En los otros períodos evaluados, la viabilidad de todas 
las líneas celulares mostró ser inferior al control de células $(p<0,05)$, reduciendo su viabilidad en función del aumento del tiempo de exposición y la concentración. Se concluye que la melitina presentó toxicidad frente a las líneas celulares estudiadas, dependiente del tiempo y la concentración.

Palabras clave: Viabilidad celular. Apitoxina. MTT.

\section{REFERÊNCIAS}

ASHTHANA, N.; YADAV, S. P.; GHOSH, J. K. Dissection os antibacterial and toxic activity of melittin: a leucine zipper motif plays a crucial role in determining its hemolytic activity bus not antibacterial activity. The Journal of Biological Chemistry, v. 279, p. 55042-55050, 2004.

BECHINGER, B. The structure, dynamics and orientation of antimicrobial peptides in membranes by multidimensional solid-state NMR spectroscopy. Biochimica et Biophysica Acta, v. 1462, p. 157-183, 1999.

BENACHIR, T.; LAFLEUR, M. Study of vesicle leakage induced by melittin. Biochimica et Biophysica Acta, v. 1235, p. 452-460, 1995.

BENTON, A.W.; MORSE, R. A.; STEWART, J. D. Venom collection from Honey Bees. Science, v. 142, p. 228-230, 1963.

BROWN, L. R.; LAUTERWEIN, J.; WUTHRICH, K. High-resolution ${ }^{1} \mathrm{H}-\mathrm{NMR}$ studies of selfaggregation of melittin in aqueous solution. Biochimica et Biophysica Acta, v. 622, n. 2, p. 231-444, 1980.

CALIXTO, J. B.; SIQUEIRA JÚNIOR, J. M. Desenvolvimento de medicamentos no Brasil: desafios. Gazeta Médica da Bahia. Bahia, v. 78, suplemento 1, p. 98-106, 2008.

CARDOSO, J. L. C.; FRANÇA, F. O. S.; WEN, F. H.; MALQUE, C. M. S.; HADDAD, J. V. Animais Peçonhentos No Brasil: Biologia, Clinica e Terapêutica dos Acidentes. São Paulo: Sarvier/Fapesp, 2003. 550p.

CERNE, K.; KRISTAN, K. C.; BUDIHNA, M. V.; STANOVNIK, L. Mechanisms of changes in coronary arterial tone induced by bee venom toxins. Toxicon, v. 56, n. 3, p. 305-312, 2010.

CERNE, K.; ERMAN, A.; VERANIC, P. Analysis of cytotoxicity of melittin on adherent culture of human endothelial cells reveals advantage of fluorescence microscopy over flow cytometry and haemocytometer assay. Protoplasma, v. 250, n. 5, p. 1131-1137, 2013.

CRUZ-LANDIM, C.; ABDALLA, F. C. Glândulas Exócrinas das Abelhas. Ribeirão Preto: FUNPEC, 2002. 182p. 
DE ABREU, R. M.; SILVA DE MORAES, R. L.; CAMARGO-MATHIAS, M. I. Biochemichal and cytochemical studies of de enzymatic activity the venom glands of workers of honey bee Apis mellifera L. (Hymenoptera, Apidae). Micron, v. 41, n. 2, p. 172-175, 2010.

DEMPSEY, C. E. The actions of melittin on membranes. Biochimica et Biophysica Acta, v. 1031, n. 2, p. 143-161, 1990.

GLÄTTLI, A.; CHANDRASEKHAR, I.; VAN GUNSTEREN, W. F. A molecular dynamics study of the bee venom melittin in aqueous solution, in methanol, and inserted in a phospholipid bilayer. European Biophysics Journal, v. 35, n. 3, p. 255-267, 2006.

GÓMARA, M. J.; NIR, S.; NIEVA, J. L. Effects of sphingomyelin on melittin pore formation. Biochimica et Biophysica Acta (BBA) - Biomembranes, v. 1612, n. 1, p. 83-89, 2003.

GORDON-GROSSMAN, M.; GOFMAN, Y.; ZIMMERMANN, H.; FRYDMAN, V.; SHAI, Y.; BENTAL, N.; GOLDFARB, D. A combined pulse EPR and monte carlo simulation study provides molecular insight on peptide-membrane interactions. The Journal of Physical Chemistry B, v. 113, p. 15128, 2009.

GORDON-GROSSMAN, M.; ZIMMERMANN, H.; WOLF, S. G.; SHAI, Y.; GOLDFARB, D. Investigation of model membrane disruption mechanism by melittin using pulse electron paramagnetic resonance spectroscopy and cryogenic transmission electron microscopy. The Journal of Physical Chemistry B, v. 116, n. 1, p. 179-188, 2012.

HABERMAN, E. Bee and Wasp Venoms. Science, v. 177, p. 314-322, 1972.

HU, H.; CHEN, D.; LI, Y.; ZHANG, X. Effect of polypeptides in bee venom on growth inhibition and apoptosis induction of the human hepatoma cell line SMMC-7721 in-vitro and Balb/C nude in-vivo. Journal of Pharmacy and Pharmacology, v. 58, n. 1, p. 83-89, 2006.

JO, M.; PARK, M. H.; KOLLIPARA, P. S.; AN, B. J.; SONG, H. S.; HAN, S. B.; KIM, J. H.; SONG, M. J.; HONG, J. T. Anti-cancer effects of bee venom toxin and melittin in ovarian cancer cells through inducion of death receptors and inhibition of JAK2/STAT3 pathway. Toxicology and Applied Pharmacology, v. 258, n. 1, p. 72-81, 2012.

JORISSEN, B. L.; BROUNS, F.; VAN BOTEL, M. P.; PONDS, R. W.; VERTHEY, F. R.; JOLLES, J.; RIEDEL, W. J. The influence of soy-derived phosphatidylserine on cognition in age-associated memmory impairment. Nutricional Neuroscience, v. 4, n. 2, p. 121-134, 2001.

KOUMANOV, K.; MOMCHILOVA, A.; WOLF, C. Bimodal regulatory effect of melittin and phospholipase A2-activating protein on human type II secretory phospholipase A2. Cell Biology International, v. 27, n. 10, p. 871-877, 2003.

LADOKHIN, A. S.; WHITE, S. H. 'Detergent-like' permeabilization of anionic lipid vesicles by melittin. Biochimica et Biophysica Acta, v. 1514, n. 2, p. 253-260, 2001. 
LEE, M. T.; HUNG, W. C.; CHEN, F. Y.; HUANG, H. W. Mechanism and kinetics of pore formation in membranes by water-soluble amphipathic peptides. Proceedings of the National Academy of Sciences, v. 105, n. 13, p. 5087-5092, 2008.

LEE, M. T.; SUN, T. L.; HUNG, W. C.; HUANG, H. W. Process of Inducing Pores in Membranes by Melittin. Proceedings of the National Academy of Sciences, v. 110, n. 35, p. 1424314248, 2013.

LIMA, J. S.; REZA, D. L.; TEIXEIRA, S.; COSTA, C. Pesquisa clínica: fundamentos, aspectos éticos e perspectivas. Revista da Sociedade de Cardiologia do Estado do Rio de Janeiro, v. 16, n. 4, p. 225-233, 2003.

LO, W. C.; HENK, W. G.; ENRIGHT, F. M. Light-microscopic studies of 3T3 cell plasma membrane alterations mediated by melittin. Toxicon, v. 35, n. 1, p. 15-26, 1997.

LU, N. Y.; YANG, K.; LI, J. L.; YUAN, B.; MA, Y. Q. Vesicle deposition and subsequent membrane-melittin interactions on different substrates: A QCM-D experiment. Biochimica et Biophysica Acta, v. 1828, n. 8, p. 1918-1925, 2013.

MAHER, S.; MCCLEAN, S. Investigation of the cytotoxicity of eukaryotic and prokaryotic antimicrobial peptides in intestinal epithelial cells in vitro. Biochemical Pharmacology, v. 71, n. 9, p. 1289-1298, 2006.

MAHER, S.; MCCLEAN, S. Melittin exhibits necrotic cytotoxicity in gastrointestinal cells which is attenuated by cholesterol. Biochemical Pharmacology, v. 75, n. 1, p. 1104-1114, 2008.

MONTANARI, C. A.; BOLZANI, V. S. Planejamento racional de fármacos baseado em produtos naturais. Química Nova, v. 24, n. 1, p. 105-111, 2001.

MOSMANN, T. Rapid colorimetric assay for cellular growth and survival: application to proliferation and cytotoxicity assays. Journal of Immunological Methods, v. 65, n. 1-2, p. 5563, 1983

MÜLLER, U.; FRICKER, M.; WYMANN, D.; BLASER, K.; CRAMERI, R. Increased specificity of diagnostic tests with recombinant major bee venom allergen phospholipase A2. Clinical \& Experimental Allergy, v. 27, n. 8, p. 915-920, 1997.

OREN, Z.; SHAI, Y. Mode of action of linear amphipathic alpha-helical antimicrobial peptides. Biopolymers, v. 47, n. 6, p. 451-463, 1998.

OWNBY, C. L.; POWELL, J. R.; JIANG, M. S.; ELETCHER, J. E. Melittin and phospholipase A2 from bee (Apis mellifera) venom cause necrosis of murin eskeletal muscle in vivo. Toxicon, $v$. 35, n. 1, p. 67-80, 1997. 
PRATT, J. P.; RAVNIE, D. J.; JIANG, X.; OROZCO, B. S.; MENTZER, S. J. Melittin-induced membrane permeability: a non osmotic mechanism of cell death. In vitro cellular \& development biology, v. 41, p. 349-355, 2005.

RAGHURAMAN, H.; CHATTOPADHYAY, A. Melittin: A membrane-active peptide with diverse functions. Bioscience Reports, v. 27, n. 4-5, p. 189-223, 2007.

RAPOPORT, R. M.; ASHRAF, M.; MURAD, F. Effects of melittin on endothelium-dependent relaxation and cyclic GMP levels in rat aorta. Circulation Research, v. 64, n. 3, p. 463-473, 1989.

REED, L. J.; MUENCH, H. A simple method of estimating fifty percent endpoints. The American Journal of Hygiene, v. 27, p. 493-497, 1938.

SU, M.; HE, C.; WEST, C. A.; MENTZER, S. J. Cytolitic peptides induce biphasic permeability changes in mammalian cell membranes. Journal of Immunological Methods, v. 252, n. 1-2, p. 63-71, 2001.

TERWILLIGER, T. C.; EISENBERG, D. The structure of melittin: II. Interpretation of the structure. The Journal of Biological Chemistry, v. 257, n. 11, p. 6016-6022, 1982.

TERWILLIGER. T. C.; WEISSMAN, L.; EISENBERG, D. The structure of melittin in the form I crystal sand its implication for melittin's lytic and surface activities. Biophysical Journal, $v$. 37, n. 1, p. 353-361, 1982.

TOSTESON, M. T.; HOLMES, S. J.; RAZIN, M.; TOSTESON, D. C. Melittin lysis of red cells. The Journal of Membrane Biology, v. 87, n. 1, p. 35-44, 1985.

VERMES, I.; HAANEN, C.; STEFFENS-NAKKEN, H.; REUTELLINGSPERGER, C.; A novel assay for apoptosis. Flow cytometric detection of phosphatidylserine expression on early apoptotic cells using fluorecein labelled Annexin V. Journal of Immunological Methods, v. 184, n. 1, p. 39-51, 1995.

WESTON, K. M.; RAISON, R. L. Interaction of melittin with a human lymphoblastoid cell line, HMy2. Journal of Cellular Biochemistry, v. 68, n. 2, p. 164-173, 1998.

WU, Y.; MA, L.; CHELEY, S.; BAYLEY, H.; CUI, Q.; CHAPMAN, E. R. I. Permeation of styryldyes through nanometer-scale pores in membranes. Biochemistry, v. 50, n. 35, p. 7493-7502, 2011.

YANG, L.; HARROUN, T. A.; WEISS, T. M.; DING, L.; HUANG, H. W. Barrel-stave model or toroidal model? A case study on melittin pores. Biophysical Journal, v. 81, n. 3, p. 14751485, 2001. 
ZHANG, N. Z.; QI, J. X.; FENG, S. J.; GAO, F.; LIU, J.; PAN, X. C.; CHEN, R.; LI, Q. R.; CHEN, Z. S.; LI, X. Y.; XIA, C.; GAO, G. F. Crystal structure of swine major histocompatibility complex class I SLA-1*0401 and identification of 2009 pandemic swine-origin influenza A H1N1 virus cytotoxic $t$ lymphocyte epitope peptides. Journal of Virology, v. 85, n. 22, p. 11709-11724, 2011.

ZHOU, J.; QI, Y.; DIAO, Q.; WU, L.; DU, X.; LI, Y.; SUN, L. Cytotoxicity of melittin and apamin in human hepatic LO2 and HepG2 cells in vitro. Journal of Toxicology Toxin Reviews, v. 32, n. 4, p. 60-67, 2013.

Autor para correspondência: Tony Picoli. Universidade Federal de Pelotas, Faculdade de Veterinária, Campus Universitário, caixa postal 354, Capão do Leão (RS), CEP 96010-900, Brasil. picolivet@gmail.com 